\title{
CAMA
}

Centre for Applied Macroeconomic Analysis

\section{Implications of Partial Information for Econometric Modeling of Macroeconomic Systems}

\section{CAMA Working Paper 41/2019 June 2019}

Adrian Pagan

School of Economics, University of Sydney

Centre for Applied Macroeconomic Analysis, ANU

\section{Tim Robinson}

Melbourne Institute: Applied Economic and Social Research, University of Melbourne

Centre for Applied Macroeconomic Analysis, ANU

\section{Abstract}

Representative models of the macroeconomy (RMs), such as DSGE models, frequently contain unobserved variables. A finite-order VAR representation in the observed variables may not exist, and therefore the impulse responses of the RMs and SVAR models may differ. We demonstrate this divergence often is: (i) not substantial; (ii) reflects the omission of stock variables from the VAR; and (iii) when the RM features I (1) variables can be ameliorated by estimating a latent-variable VECM. We show that DSGE models utilize identifying restrictions stemming from common factor dynamics reflecting statistical, not economic, assumptions. We analyze the use of measurement error, and demonstrate that it may result in unintended consequences, particularly in models featuring I (1) variables. 


\title{
Keywords
}

SVAR, Partial Information, Identification, Measurement Error, DSGE

\author{
JEL Classification
}

E37, C51, C52

Address for correspondence:

(E) cama.admin@anu.edu.au

ISSN 2206-0332

The Centre for Applied Macroeconomic Analysis in the Crawford School of Public Policy has been established to build strong links between professional macroeconomists. It provides a forum for quality macroeconomic research and discussion of policy issues between academia, government and the private sector.

The Crawford School of Public Policy is the Australian National University's public policy school, serving and influencing Australia, Asia and the Pacific through advanced policy research, graduate and executive education, and policy impact. 


\title{
Implications of Partial Information for Econometric
}

\author{
Modeling of Macroeconomic Systems ${ }^{\mathrm{a}}$
}

\author{
Adrian Pagan ${ }^{\mathrm{b}}$ and Tim Robinson ${ }^{\mathrm{c}}$
}

June 17, 2019

\begin{abstract}
Representative models of the macroeconomy (RMs), such as DSGE models, frequently contain unobserved variables. A finite-order VAR representation in the observed variables may not exist, and therefore the impulse responses of the RMs and SVAR models may differ. We demonstrate this divergence often is: (i) not substantial; (ii) reflects the omission of stock variables from the VAR; and (iii) when the RM features I(1) variables can be ameliorated by estimating a latent-variable VECM. We show that DSGE models utilize identifying restrictions stemming from common factor dynamics reflecting statistical, not economic, assumptions. We analyze the use of measurement error, and demonstrate that it may result in unintended consequences, particularly in models featuring $\mathrm{I}(1)$ variables.
\end{abstract}

Keywords: SVAR; Partial Information; Identification; Measurement Error; DSGE. JEL codes: E37; C51; C52.

\footnotetext{
${ }^{a}$ An earlier version of this appeared under a different title as Pagan and Robinson (2016); it also contains material from the working paper Pagan (2017). We thank Mariano Kulish for comments on this and an earlier version. We also thank participants at the 2016 Padova Macro Talks, seminars at the University of Tasmania and Adelaide, Efrem Castelnuovo, Viet Nguyen, Giovanni Pellegrino and Sarantis Tsiaplias for comments on an earlier version. All errors are our own. This work was supported by ARC Grant DP160102654.

${ }^{\mathrm{b}}$ Emeritus Professor, School of Economics, University of Sydney and Honorary Professor, CAMA, Australian National University. adrian.pagan@sydney.edu.au.

${ }^{\mathrm{c}}$ Senior Research Fellow, Melbourne Institute: Applied Economic and Social Research, University of Melbourne, and Research Associate, CAMA, Australian National University. tim.robinson@unimelb.edu.au. Corresponding author.
} 


\section{Introduction}

A wide variety of modeling strategies are now used in macroeconometrics. Generally all models intended for policy analysis involve structural aspects but differ in their scale, the extent to which they impose strong theoretical ideas upon the data, and the particular purpose for which they are constructed. Examples include: large-scale Dynamic Stochastic General Equilibrium (DSGE) models - e.g. the Federal Reserve's EDO model (Chung et al. 2010) and the Multi-Sector Model of Rees et al. (2016); macroeconometric models, such as FRB/US and MARTIN of the Reserve Bank of Australia, that try to strike a balance between the data and theory; components models, e.g. Fleischman and Roberts (2011) from the Federal Reserve, which aim to capture a critical quantity for policy, such as the output gap; and Structural Vector AutoRegression (SVAR) models, which are oriented more towards the data than the theory. ${ }^{1}$

SVARs are often used to see if the structure being employed in the more theoretical models is consistent with the data. An example is Brayton, Laubach and Reifschneider (2014, p.4), who say, in the context of the Federal Reserve's FRB/US model, that: "The responses of the output gap and inflation to a permanent increase in multi-factor productivity are also in general accordance with estimates from the VAR literature of the effects of technology shocks." Whether SVARs can be used effectively for such comparisons depends on whether they can closely match the impulse responses of a model that is taken to represent the actual economy, which we term the Representative Model (RM).

The use of partial information in the SVAR is a potentially important factor influencing the ability to make such a match. The loss of information can arise from a number of sources. One of these is due to scale - there may be more variables in the RM than in the SVAR, as SVARs typically only include measured variables. In Section 2, using data simulated from several different well-known RMs taken from the literature, we demonstrate

\footnotetext{
${ }^{1}$ There have always been a large range of models used for forecasting but we are concerned here with models constructed to enable the examination of policy options.
} 
what approximation difficulties this source of partial observability causes, and when it may be minor. The omission of stocks of capital, foreign debt in open economies, and the use of concepts such as flexible-price equilibria emerge as instances where it is quantitatively important. We discuss what can be done to improve the match of the impulse responses in those contexts.

The analysis of Section 2 initially assumes that all variables in the model are $I(0)$. We subsequently consider models which also include variables that are $I(1)$, that is, they contain a mixture of permanent and temporary shocks. This can introduce partial observability into the growth rates of some I(1) variables, as the available data on their growth does not exactly measure them. Allowing for this gap means that there are latent variables in the SVAR and we show how these can be accommodated. Our findings suggest that an important factor contributing to the divergent findings which exist in the literature about the ability of SVARs to make a match with the impulse responses from DSGE models is whether or not the DSGEs being analyzed include permanent shocks.

The presence of unobserved variables is not the sole source of partial information. SVARs often do not fully use the restrictions that are embedded in the RM, which may affect the identification of the SVAR. One such restriction is that structural shocks in DSGE models are typically assumed to be univariate autoregressive processes. This turns out to be a strong identifying assumption. Hence we explore what happens if the SVAR format is retained but the assumption about the statistical nature of shocks in RMs is exploited. This is not a restriction that comes from economic theory. It produces a common factor in the parameters that a SVAR would normally lack. We find that this can be very important in the identification of the SVAR. Section 3 utilizes a small scale New-Keynesian model as the RM to illustrate the importance of these common-factor restrictions.

Section 4 examines the last potential source of partial information and its effects. In Section 2 when variables were $I(1)$ there was a potential gap between the growth rates of model variables and the observed data and this mismatch was accounted for by model shocks. 
However, there has been an increasing tendency to allow for any mismatch between data and model variables $(I(0)$ as well as $I(1))$ to be reconciled by the use of "measurement errors". Unlike the use of model shocks this is researcher initiated and does not flow from the model. We describe the problems that can occur when measurement errors are used, particularly in models including I(1) variables, and how they can be mitigated. Section 5 concludes.

\section{Implications of Partial Observability for SVAR Ap- proximations}

We start by making a distinction between the endogenous and exogenous variables in the modern structural models used in macroeconometrics. The latter are taken to be shocks and are strongly exogenous, i.e. they depend only on their own history. The solution to many RMs will be a $\operatorname{VAR}(\mathrm{p})$ process, typically a low-order (e.g. $p=2$ ), expressing all the endogenous variables as a function of innovations into these shocks. Simplification may be possible, as often some of the endogenous variables may be substituted out of the system by using identities, leaving a core set of endogenous variables and shocks. However, when a SVAR is applied to data simulated from such a RM, not all of the core variables may be directly observed. This could either reflect the fact that the model variables have no counterpart in the actual data or a decision by the researcher. A consequence of this partial observability is that the estimated SVAR may need to be of much higher order (possibly infinite) for its impulse responses to match those of the RM.

The question is whether we would expect a very high-order SVAR to be needed and what factors would make that so. The existing literature is inconclusive on this issue. For example, Chari, Kehoe and McGrattan (2005) argued that SVARs could not capture the impulse responses of the RM, whereas Christiano, Eichenbaum and Vigfusson (2007) were more optimistic. Kapetanios, Pagan and Scott (2007), using as the RM an economy-wide model that was a miniature version of the Bank of England's model in the 2000s, found a 
very high-order SVAR to be necessary.

In practice applied researchers typically use a low-order SVAR; two or four lags is common. Hence we look at whether such orders would suffice when several DSGE models from the literature are taken as the RMs. If they fail to match we describe this as a truncation error, in that the dynamics are not of high enough order. In doing this we note that the impulse responses of the SVAR depend upon the initial response $C_{0}^{S V A R}$ and the VAR coefficients $B_{1}^{S V A R}, \ldots, B_{p}^{S V A R}$, while the corresponding RM quantities are $C_{0}^{R M}$ and the implied VAR coefficients from its solution are $B_{1}^{R M}, \ldots, B_{p}^{R M}$. To focus upon the approximation of the dynamics we set $C_{0}^{S V A R}=C_{0}^{R M}$, as done by Ravenna (2007) and Kapetanios, Pagan and Scott (2007), so that any discrepancy between responses is due to differences between the VAR coefficients. Hence it reflects a problem in capturing the dynamics and we will refer to this as an issue in estimating a VAR, rather than a SVAR.

We find that a reasonable match can often be obtained with the low lag lengths typically used in applied work, particularly if care is taken with respect to the selection of the variables that are included in the VAR. Section 2.2 discusses the role of stock variables in determining the extent of truncation error. An important example which arises is the stock of net foreign assets in small-open economy models. These serve as part of a stabilizing mechanism which will be absent if it is omitted from a VAR. Including such stock variables is not typical in VAR models. It emerges that, when there are no omitted stocks and the observed variables are stationary, truncation error is typically not a major issue. This is true when using a $\operatorname{VAR}(4)$ as an approximation, but is even the case when a $\operatorname{VAR}(2)$ is adopted.

Today RMs often include permanent shocks - typically the log of technology - together with transitory disturbances, such as monetary policy shocks. These permanent shocks result in some variables having a common permanent component and that produces cointegration between core I(1) endogenous variables and an exogenous I(1) latent variable, such as technology. This is handled in RMs such as DSGE models by working with I(1) variables that have been transformed to stationarity by using a permanent I(1) component, 
while the stationary variables are left in their levels. At least one of the transformed I(1) variables will be latent, while the others can be formulated as observable error-correction (EC) terms. A Vector Error-Correction Model (VECM) formulation in observed variables will omit the latent EC term. Hence there is a specification error in using such a VECM.

In Section 2.3 we find that when the RM features permanent shocks the truncation error may be significant. We describe an alternative approach that involves estimating a latentvariable VECM. Using an example from Poskitt and Yao (2017) we show that this approach can considerably lessen the truncation error. In the literature to date, for example Del Negro, Schorfheide, Smets and Wouters (2007), only observed EC terms have been included in the observed-variable VECM, and the latent EC term has been omitted.

Our analysis shows that the magnitude of truncation error which occurs with a SVAR is likely to depend on the nature of the shocks included in the RM. This is an explanation of the divergent findings in the literature - for example, Chari et al. (2005) included a permanent shock, whereas Christiano et al. (2007), who were more optimistic, only included transitory disturbances.

\subsection{Analysis: Truncation Bias with I(0) Variables}

This sub-section presents a simple framework to illustrate the issues that may arise in VAR analysis due to information being only partially observed. A common approach to studying the relationship between the modeling approaches of VARs and RMs is to write the RM in state-space form, so as to separate the latent and observed variables - the ABCD representation - before finding the conditions for a finite-order VAR representation (FernándezVillaverde, Rubio-Ramírez, Sargent and Watson 2007). This approach was adopted by Ravenna (2007), Franchi and Vidotto (2013) and Morris (2016); Giacomini (2013) surveys that literature. ${ }^{2}$

Our focus is different. Rather than deriving the conditions necessary for the existence

\footnotetext{
${ }^{2}$ Canova and Ferroni (2018) use the ABCD representation to examine some of the issues we address in Section 2 of the paper.
} 
of a finite-order VAR representation, we instead investigate how well a low-order VAR, akin to those used by applied researchers, can match the impulse responses of the RM. The framework emphasizes that what is crucial is the ability of the observed variables to explain the unobserved variables. This demonstrates the issues that may arise when there is only partially observability.

Historically, all variables in RM models were taken to be $I(0)$, and their solution was a $\operatorname{VAR}(p)$. For convenience we set $p=2$, giving the solution ${ }^{3}$

$$
z_{t}=B_{1} z_{t-1}+B_{2} z_{t-2}+H \varepsilon_{t}
$$

where $z_{t}$ are the core endogenous variables of the RM, and $\varepsilon_{t}$ the structural shocks with unitary standard deviation. $z_{t}$ can be divided into those upon which there are data, $z_{t}^{o}$, and those that are unobserved, $z_{t}^{u}$. As is common in RMs it will be assumed that there are the same number of shocks $\varepsilon_{t}$ as observed variables, and that the rank of $H$ is $n^{o}=\operatorname{dim}\left(z_{t}^{o}\right)$. From the singular value decomposition of $H$ there exists an $n \times n\left(n=\operatorname{dim}\left(z_{t}\right)\right)$ orthogonal matrix $S$ such that $S H=\left[\begin{array}{c}G \\ 0\end{array}\right]$, where $G$ is of rank $n^{o}$. Then

$$
S z_{t}=S B_{1} z_{t-1}+S B_{2} z_{t-2}+\left[\begin{array}{c}
G \\
0
\end{array}\right] \varepsilon_{t}
$$

Partioning $S$ as $\left[\begin{array}{cc}S_{o o} & S_{o u} \\ S_{u o} & S_{u u}\end{array}\right]=\left[\begin{array}{c}S_{1} \\ S_{2}\end{array}\right]$ gives the second set of equations as an identity

$$
S_{u u} z_{t}^{u}=-S_{u o} z_{t}^{0}+S_{2} B_{1} z_{t-1}+S_{2} B_{2} z_{t-2} .
$$

\footnotetext{
${ }^{3}$ See Binder and Pesaran (1995). The conditions for the solution are two-fold: a rank condition and the Blanchard-Kahn stability conditions must be satisfied (Blanchard and Kahn 1980).
} 
Since $S_{u u}$ is non-singular we could write Equation (2) as

$$
\Psi(L) z_{t}^{u}=H(L) z_{t}^{o}
$$

where $\Psi(L)=I-\Psi_{1} L-\Psi_{2} L^{2}, H(L)=H_{0}+H_{1} L+H_{2} L^{2}$ and this will mean that $z_{t}^{u}=$ $\sum_{j=0}^{\infty} F_{j} z_{t-j}^{o}$, i.e. the unobserved variables can be expressed as a combination of the current and lagged observables. This demonstrates that it is possible to recover the unobserved variables from the observed variables using their contemporaneous values and enough lags. After substituting for $z_{t}^{u}$ in the first block we get that the observable variables follow a process

$$
D(L) z_{t}^{o}=G \varepsilon_{t}
$$

where $D(L)$ may be an infinite polynomial in $L$.

Suppose we had assumed that the VAR in $z_{t}^{o}$ was a first-order VAR. Hence, if one just regressed $z_{t}^{o}$ on $z_{t-1}^{o}$ there would be a misspecification due to the omission of the term $\psi_{t}=\sum_{j=2}^{\infty} D_{j} z_{t-j}^{o}$. When $z_{t-1}^{o}$ and $\psi_{t}$ are uncorrelated there will be no bias in the estimated coefficients of $z_{t-1}^{o}$. Nevertheless, the impulse responses to the shocks $\varepsilon_{t}$ would be incorrect because of the omission of the higher-order lags in $z_{t}^{o}$ from the system when impulse responses are computed. If the variables are correlated there is also a bias in the estimates of the coefficients of $z_{t-1}^{o}$. Hence the misspecification has two effects and these will depend upon the magnitude of $D_{j}(j=2, \ldots)$ and the correlation of $z_{t-1}$ with $\psi_{t}=\sum_{j=2}^{\infty} D_{j} z_{t-j}^{o}$. Of course if we used a $\operatorname{VAR}(\mathrm{M})$, rather than the first order, the same effects will be observed, except that $\psi_{t}=\sum_{j=M+1}^{\infty} D_{j} z_{t-j}^{o}$.

To summarize, this analysis has demonstrated that information being only partially observed has implications for a VAR in that, while it is possible to recover the unobserved variables from the observed variables, this may require more lags than is typically used (or is feasible in finite samples). Consequently, if these higher-order terms are correlated with those that are included, there may be an omitted-variable bias. Even in the absence of any 
such bias the omission will result in the computed impulse responses being incorrect. The fundamental question revolves around the size of this truncation bias.

\subsection{Sources of Truncation Bias: Transitory Shocks}

We now turn to discussing specific aspects of RMs that are likely to contribute to the extent of truncation error in the observed-variables VAR.

\subsubsection{Absence of Stock Variables in a VAR}

VAR models are frequently estimated using only flow variables, such as the level of economic activity. RMs alternatively have both flow and stock variables, such as investment and the stock of capital. Akin to the VAR, the observed variables used to estimate DSGE models typically only include the flow variables, but the model incorporates an identity linking the stocks and flows. In some cases this identity can be used to expressed the stock in terms of flow variables and the shocks, e.g. if the production function is Cobb-Douglas then the log of capital can be expressed in terms of the logs of output, labor and the technology shock. Hence the capital stock can be eliminated, leaving output and labor as the core endogenous variables.

In cases where it is not possible to eliminate stock variables, their absence from the observed-variables SVAR does not necessarily mean that truncation bias will be sizable. As an example, the solution to a simple RBC model, such as Uhlig (1999), with only the log of output being observable, can be well approximated by even a simple AR(1) model in $y_{t}$. This is also true for some more complex variants of RBC models; for example, if one introduces a preference shock and matches this with a second observed variable. If hours worked is chosen as the latter then the latent capital stock can be eliminated, highlighting that careful choice of the observed variables can eliminate potentially important unobserved stock variables, thereby diminishing truncation error. 


\subsubsection{Small-Open Economy Models}

Small-open economy models are a case where unobserved stock variables may have a considerable influence on the ability to make a match between the impulse responses. Consider, for example, the small-open economy model of Justiniano and Preston (2010); this has thirtyfour endogenous variables and twelve shocks. Many of the endogenous variables in the model can be substituted out using identities. Such a process leaves thirteen core variables, of which one is unobserved, namely the level of net foreign assets. This is the only stock variable in the RM since capital is not included. Using their parameter values, the Justiniano and Preston (2010) system has the following equation for output

$$
\begin{aligned}
y_{t}= & 1.49 y_{t-1}-.52 y_{t-2}-.026 y_{t-1}^{*}+.017 y_{t-2}^{*}-.032 i_{t-1}^{*}+.036 \pi_{t-1}^{*} \\
& -.0004 \pi_{t-2}^{*}+.004 w_{t-1}^{*}-.001 w_{t-2}^{*}+.003 h_{t-1}^{*} \\
& +.241 i_{t-1}-.06 q_{t-1}+.06 q_{t-2}-.22 \pi_{t-1}+.004 \pi_{t-2}-.04 w_{t-1} \\
& +.018 w_{t-2}-.024 h_{t-1}-.04 s_{t-1}+.036 s_{t-2}-.0001 B_{t-1}+e_{y t}
\end{aligned}
$$

where domestic output, interest rate and inflation are $y_{t}, i_{t}$ and $\pi_{t}$ respectively, and a $*$ denotes their foreign counterparts. Other variables include the nominal and real exchange rates $\left(s_{t}\right.$ and $\left.q_{t}\right)$, real wages $\left(w_{t}\right.$ and $\left.w_{t}^{*}\right)$, hours $\left(h_{t}\right.$ and $\left.h_{t}^{*}\right)$, and the level of net foreign assets $B_{t}$. The VAR error $e_{y t}$ is a function of the structural shocks. Equation (4) is an identity. ${ }^{4}$ Even though it is not a structural equation, it contains information about the impact of structural shocks; the contemporaneous impulse response matrix $C_{0}$ can be computed from

\footnotetext{
${ }^{4}$ Throughout this paper the identities governing the evolution of variables were found by simulating data from the TM and then fitting regressions, where the innovations to the structural shocks are included with the core variables as explanatory variables. Because these are identities they have perfect fit. They are distinct from the decision rules, such as those produced by Dynare, as they are expressed only in terms of the core variables and the shock innovations.
} 
the coefficients of $\varepsilon_{t}$ in

$$
\begin{aligned}
e_{y t}= & -.034 \varepsilon_{t}^{a}-.011 \varepsilon_{t}^{a^{*}}+.17 \varepsilon_{t}^{g}+.042 \varepsilon_{t}^{g^{*}}-1.495 \varepsilon_{t}^{i}+.094 \varepsilon_{t}^{i^{*}} \\
& +.09 \varepsilon_{t}^{c p^{*}}-.386 \varepsilon_{t}^{c p h}-.022 \varepsilon_{t}^{c p f}+.0002 \varepsilon_{t}^{n}+.00005 \varepsilon_{t}^{n^{*}}+.65 \varepsilon_{t}^{r p},
\end{aligned}
$$

where the structural shocks are for preferences $\left(\varepsilon_{t}^{g}, \varepsilon_{t}^{g^{*}}\right)$, technology $\left(\varepsilon_{t}^{a^{*}}, \varepsilon_{t}^{a}\right)$, monetary policy $\left(\varepsilon_{t}^{i}\right.$ and $\left.\varepsilon_{t}^{i^{*}}\right)$, cost push shocks in the foreign economy and to the foreign and domestic goods in the domestic economy $\left(\varepsilon_{t}^{c p^{*}}, \varepsilon_{t}^{c p h}, \varepsilon_{t}^{c p f}\right.$ respectively), labor supply $\left(\varepsilon_{t}^{n}\right.$ and $\left.\varepsilon_{t}^{n^{*}}\right)$ and the risk premium $\left(\varepsilon_{t}^{r p}\right)$. As an example, from Equation (5) the contemporaneous response of output to a domestic monetary policy shock is -1.495 . Consequently, we will refer to the solution in this form as a Semi-Structural VAR (SSVAR).

The left-hand panel of Figure 1 presents the impact of a domestic monetary policy shock upon output using a $\operatorname{SSVAR}(2)$ with all variables from the RM, as well as one with just the observed variables with 2 and 4 lags. All the impulse responses presented in this paper are for a one unit shock. There is very little difference between them; the response of inflation to a monetary shock is approximated with only two lags, as is the case for the real exchange rate.

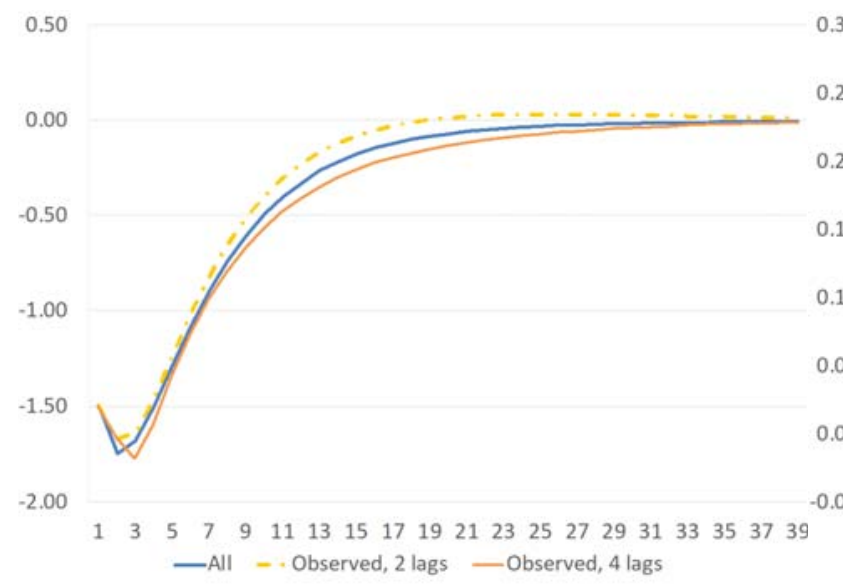

(a) Output to a Domestic Monetary Shock

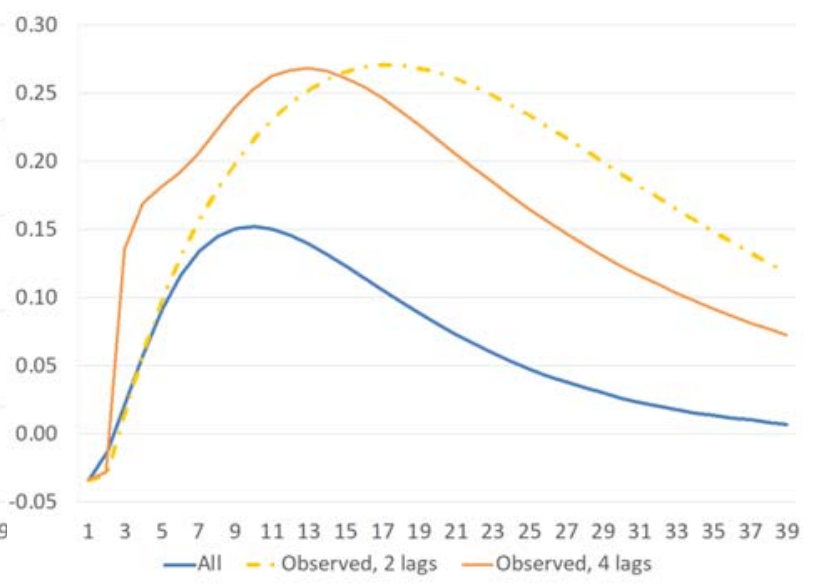

(b) Output to a Domestic Technology Shock

Figure 1: Impulse Responses for VARs Fitted to the Justiniano and Preston (2010) Model Output with (i) All Variables; (ii) the Observed Variables with Two Lags, and (iii) the Observed Variables with Four Lags. 
In contrast, the right-hand panel of Figure 1 shows the response of output to the domestic technology shocks; in this case there is a difference, especially as the horizon lengthens. In particular, it takes far longer for the observed-variables SSVAR estimates of the responses to die away. This pattern can be seen in a number of other impulse responses, such as the response of the real exchange rate to technology shocks. Essentially, in relation to real shocks, such as technology, the complete system returns to the steady-state position much faster than a SSVAR which omits foreign asset balances.

The logic underlying the failure to make a match is that the inclusion of a debt-elastic premium is a common way of closing small-open economy DSGE models; see Schmitt-Grohe and Uribe (2003). Without such a stabilizing mechanism - and it will be absent in a SVAR that does not include debt - we would expect that convergence to any steady state will be far slower, and might not even occur. Indeed, the estimated dynamics of the VAR equation for the real exchange rate change markedly when debt is included. ${ }^{5}$

This result sheds light on the findings of Kapetanios et al. (2007), who studied a smallopen model of the type used by Justiniano and Preston (2010) as their RM. They concluded that one needed a VAR of order 50 and 30,000 observations to capture the responses. They also found that it took much longer to return to the steady state. Foreign assets were treated as unobserved and so omitted from the VAR, and our results suggest that this will have been an important factor contributing to the difficulties they encountered in making a match.

In all, it appears that treating the level of foreign debt or assets as unobserved in VARs of small-open economies is very likely to be an issue in obtaining a correct measure of the dynamics of real shocks. For this reason every effort should be made to measure such a variable in small-open economy SVARs. If it is difficult to measure the debt variable one possibility might be to include both absorption and domestic output as observed variables in the VAR. The difference between absorption and domestic output captures the trade

\footnotetext{
${ }^{5}$ This suggests that debt is highly correlated with the included variables and this is the case - regressing debt on the observed variables produces an $R^{2}$ of .99 . Consequently, omitting debt from the system will produce biased estimates of the dynamics.
} 
account balance and hence may approximate the evolution of debt. Imposing an identity on the SVAR related to this balance and the interest on debt is also an option - see Ouliaris et al. (2018).

\subsubsection{Flexible-Price Output Gaps}

Sizable truncation bias can arise in closed-economy VARs for other reasons. An example is the inclusion in the RM of a parallel system that describes an economy with flexible prices. In that case, the monetary policy reaction function responds to a measure of the output gap defined as the difference between the actual and the flexible-price (flex-price) level of output. This introduces the flex-price level of the capital stock as an unobserved core variable. Whether this is important for the VAR approximation depends on how well it can be approximated by lags of the observed variables and the bias in the parameter estimates occurring due to its omission.

To gauge the magnitudes of these effects, we take the Smets and Wouters (2007) NewKeynesian model of the United States economy as the RM. ${ }^{6}$ It has a large number of endogenous variables (twenty-four), but only ten core ones. There are seven shocks and, consequently, seven observed variables. The SSVAR therefore includes three unobserved variables.

Stock variables are two of the three unobserved core variables, namely capital, $k_{t}$, and the flex-price level of capital, $k f_{t}$, together with the price of capital, $p k_{t}{ }^{7}$ To assess the ability to proxy these latent variables with the observed data we regress $k_{t}, k f_{t}$ and $p k_{t}$ against two lags of the observed variables and obtain $R^{2}$ values of $.96, .53$ and .08 , respectively, indicating that it varies considerably. Offsetting this, however, is the fact noted previously

\footnotetext{
${ }^{6}$ In its original form the mark-up shocks in the Phillips curves are ARMA processes and consequently the solution will not be a finite-order VAR. However, in this section we replace those ARMA terms with standard AR processes.

${ }^{7}$ The production function in Smets and Wouters (2007) has capital services in it, which can be found from output, hours and technology. However, these are allowed to vary with utilization of the lagged capital stock. Consequently, either the capital stock or the utilization rate are not observable and will be a latent core variable.
} 
that a low $R^{2}$ would mean less of a bias in the parameter estimates when the latent variables are omitted. when

Akin to the small-open economy model, the effects of monetary policy shocks on inflation are little affected by the use of a $\operatorname{VAR}(2)$ in the observed variables alone. Alternatively, the real shocks, such as technology, do have differing response functions, but by far less than was apparent in the small-open economy model (left-hand side of Figure 2). It is notable that the observed-variables VAR now has impulse responses which converge to zero much faster than the RM. The reason for this is that much of the persistence comes from the omitted stock variables. However, unlike the case of foreign debt, capital stocks do not act as a stabilizing device, but make the adjustment longer.

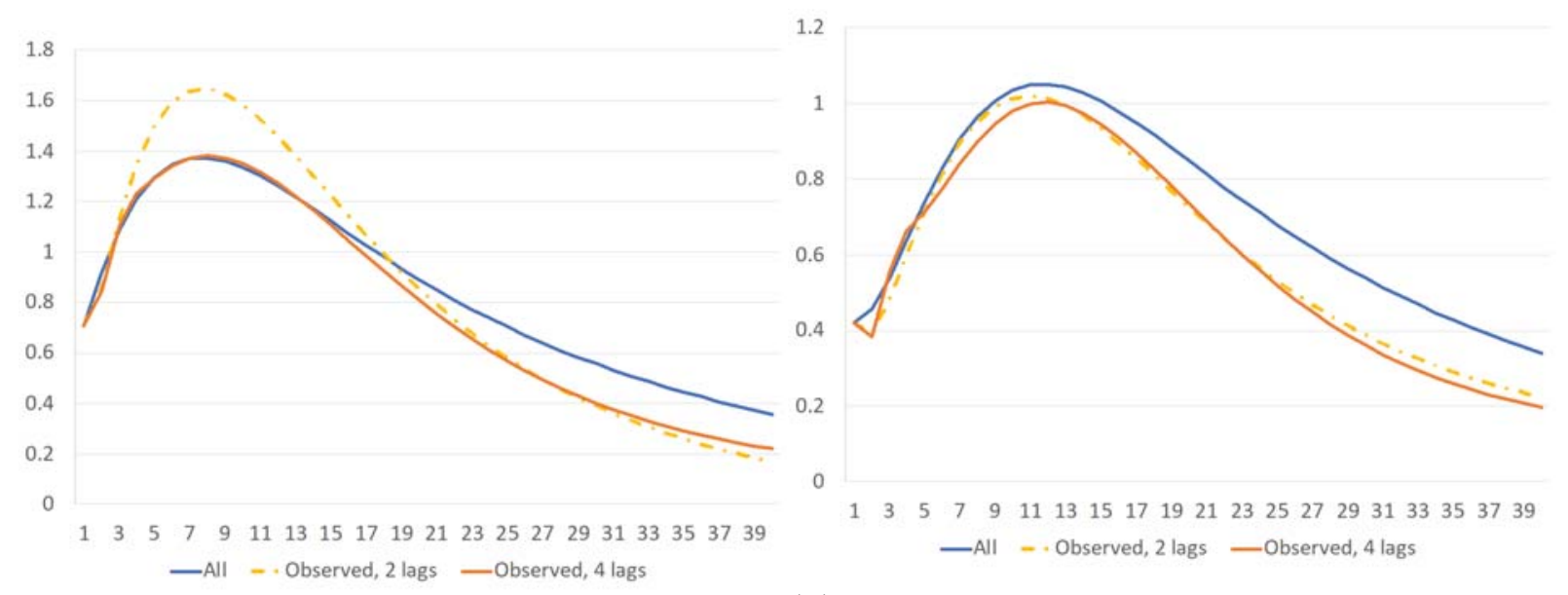

(a) Output to a Technology Shock

(b) Output to a Technology Shock - No Flex-Price Terms

Figure 2: Impulse Responses for VARs Fitted to the Smets and Wouters (2007) Model Output with (i) All Variables; (ii) the Observed Variables with Two Lags, and (iii) the Observed Variables with Four Lags.

The importance of the flex-price level of the capital stock can be assessed by modifying the monetary policy reaction function, which is the sole place where the flex-price variables enter the sticky-price economy. While a flex-price output gap often appears in theoretical models, in many applied models the interest rate is instead directly related to $y_{t}$, the log deviation of output from its steady state. Modifying the monetary rule in this way eliminates $k f_{t}$ from the model. The right-hand panel of Figure 2 shows the same impulse response, 
but with the modified monetary rule. The observed-variables $\operatorname{SSVAR}(2)$ responses are now a much better match. One might have expected this change to have significantly altered the impulse responses for monetary policy shocks, but these are similar for either variant of the RM. In summary, the inclusion of the flex-price output gap in the monetary rule plays an important role in limiting the ability of a VAR to make a match.

\subsection{Sources of Truncation Bias: Permanent Shocks}

\subsubsection{Analysis}

It has become common for DSGE models to include permanent shocks. An example is if the log-level of technology, $a_{t}$, is assumed to follow a unit root. As the economy in this case will have a long-run growth path, a normalization has to be used prior to log-linearization of the model for estimation. For example, consider the consumption Euler equation with log utility, namely $C_{t}^{-1}=\beta E_{t} C_{t+1}^{-1} R_{t+1}$, where $C_{t}$ is the level of consumption, $\beta$ the discount factor and $R_{t}$ is a real interest rate. The appropriate normalization would be $A_{t} \equiv \exp \left(a_{t}\right)$, and the Euler equation would become $\left(\frac{C_{t}}{A_{t}}\right)^{-1}=\beta R^{*} E_{t}\left(\frac{C_{t+1}}{A_{t+1}}\right)^{-1}\left(\frac{A_{t+1}}{A_{t}}\right)^{-1} \frac{R_{t+1}}{R^{*}}$, with $R^{*}$ the steady-state interest rate. Then, after log-linearization, we have

$$
c_{t}-a_{t}=E_{t}\left[c_{t+1}-a_{t+1}+\Delta a_{t+1}\right]-E_{t} r_{t+1}+r^{*},
$$

where the lower case letters represent the logs of the upper case ones.

It is apparent that the inclusion of a permanent technology shock results in some variables in these models being $\mathrm{I}(1)$ and co-integrated. An example of such co-integration is that between $c_{t}$ and $a_{t}$, since $c_{t}-a_{t}$ is $\mathrm{I}(0)$ in Equation (6). All the model variables which are I(1) are expressed as deviations from $a_{t}$, a process often referred to as "stationizing". These variables are $I(0)$ and represent the error-correction (EC) terms.

As before, the solution to the RM will be a VAR in the core variables, $z_{t}$. However, some of these will be the stationized variables, such as $c_{t}-a_{t}$ (denoted with a superscript $S$, i.e. $c_{t}^{s}$ ). 
Now $c_{t}^{s}$ is not directly observed, but may be related to the observed data. As an example, let $\Delta c_{t}$ be observed data on consumption growth. Then $\Delta c_{t}=\Delta\left(c_{t}-a_{t}\right)+\Delta a_{t}=\Delta c_{t}^{S}+\Delta a_{t}$. A way to handle such a variable is to add a statistical specification for the latent exogenous process $a_{t}{ }^{8}$ Doing so yields a latent-variable VECM. As we will show, estimating such a model can mitigate truncation error relative to alternative specifications.

\subsubsection{Extent of Truncation Bias}

Poskitt and Yao (2017) and Ravenna (2007) studied the extent of truncation bias in a simple RBC RM when there was non-stationary technology. They have two core observed variables - output, $y_{t}$, and hours, $h_{t}$. As the latent capital stock can be substituted out from their $\mathrm{RM}$, the only core endogenous latent variable is stationized output, $y_{t}^{S}$.

The RM is a $\operatorname{SSVAR}(1)$ in $y_{t}^{S}$ and $h_{t}$. As $y_{t}^{S}=y_{t}-a_{t}$, this can be differenced to obtain $\Delta y_{t}=\Delta y_{t}^{S}+\Delta a_{t}$, and the SSVAR(1) of their RM expressed in terms of the observed variables, $\Delta y_{t}$ and $h_{t}$ will be

$$
\begin{aligned}
\Delta y_{t} & =-.01 h_{t-1}-.18 y_{t-1}^{S}-1.56 \varepsilon_{t}^{h}+.96 \varepsilon_{t}^{a} \\
h_{t} & =.93 h_{t-1}-.24 y_{t-1}^{S}-2.4 \varepsilon_{t}^{h}+.48 \varepsilon_{t}^{a} .
\end{aligned}
$$

Note that lagged stationized output $y_{t-1}^{S}$ remains in the system. It cannot be eliminated. The system is a latent variable Semi-Structural Vector Error-Correction Model, where $y_{t-1}^{S}$ is the lagged error-correction term between observed output and the latent technology process. Any SSVAR in the observed variables alone, that is omitting $y_{t-1}^{S}$, would be misspecified.

How important would the specification error be from ignoring the EC term? The magnitude of the resulting bias in Equation (7) will depend on the relative variances of -. $18 y_{t-1}^{S}$ and $\left(-1.56 \varepsilon_{t}^{h}+.96 \varepsilon_{t}^{a}\right)$. The ratio is 0.33 , which suggests that the bias may be sizable. ${ }^{9} \mathrm{~A}$

\footnotetext{
${ }^{8}$ In contrast, there can be stationized variables that do not relate directly to data and which require an economic model for their construction, such as the capital stock when there is a variable utilization rate.

${ }^{9}$ Omitting $y_{t-1}^{S}$ from Equation (7) yields an estimate of the coefficient of $h_{t-1}$ of -.097 (compared with -0.01), while for Equation (8) it produces .83, rather than .93. Consequently, the impact of shocks on $\Delta y_{t}$
} 
reasonable rule of thumb is that when the EC term's coefficient is small we can work with a VAR in differences for the I(1) variables.

Figure 3 shows the divergence between the impulse response of hours to a technology shock obtained from a VAR using the observed and all variables. This difference is much the same as reported in Poskitt and Yao (2017). The divergence is due to bias in the $h_{t-1}$ coefficient estimate.

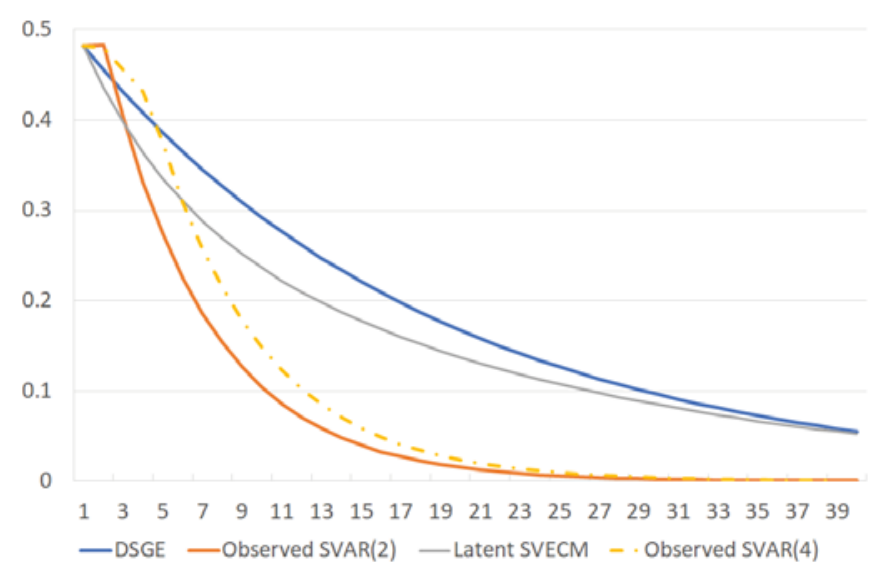

Figure 3: Impulse Response of Hours to a Technology Shock Using: (i) the RM of Poskitt and Yao (2017) (DSGE); (ii) a VAR(2) in the Observed Variables; (iii) a Latent-variable VECM and (iv) a $\operatorname{VAR}(4)$ in the Observed Variables

To examine whether the biases could be mitigated by using a higher number of lags we regress $y_{t}^{S}$ upon $\left\{h_{t-j}, \Delta y_{t-j}\right\}_{j=1}^{M}$. When $M=2$ we obtain an $R^{2}$ of .7 ; it is necessary to use $M=50$ to reconstruct the latent variable from the observed variables. Since there is a high correlation between $h_{t-1}$ and $y_{t-1}^{S}$, there will be a bias in the estimates of the coefficient on $h_{t-1}$, as already seen in the comparison of the impulse responses.

As adding lags to the VAR is unlikely to deliver a good match without using an impractically high lag length, what other strategies are available? One is to recognize that the system is a latent-variable $V E C M$, and to augment the system with an assumption about the latent exogenous technology process (as is done in DSGE models). Then the latent VECM can be estimated as a state-space model using the Kalman filter. We assume that technology

will die out very quickly, even though there is a bias in the estimates. In contrast, the difference in the parameter values in Equation (8) for $h_{t-1}(.93$ and .83$)$ results in very different decay rates for the impulse responses of $h_{t}$. 
follows an I(1) process, consistent with the RM that Poskitt and Yao (2017) use, and the implied state-space model is provided in the Appendix.

Figure 3 shows the impulse response of hours worked to a technology innovation from this latent variable VECM, which closely matches the impulse response from the RM. So estimating a latent-variable VECM is a potentially useful strategy when the RM is believed to have non-stationary technology. It may not be necessary to do this as any bias that emerges will depend on the relative variances of the omitted EC term and the structural shocks in the equation that has the change in an I(1) variable as the dependent variable. An example is the model of An and Schorfheide (2007). There the variance of the shock in the structural equation for output growth is ten times larger than that of the omitted EC term. Consequently the bias is slight. ${ }^{10}$

Often one sees a VECM being used that incorporates only observed EC terms. An example is Del Negro, Schorfheide, Smets and Wouters (2007), who introduce an I(1) technology shock, $a_{t}$, into the Smets and Wouters (2007) model. As before, the normalized variables include the EC terms $\left(y_{t}-a_{t}\right),\left(c_{t}-a_{t}\right)$ and $\left(i_{t}-a_{t}\right)$. These can be written equivalently as $\left(y_{t}-a_{t}\right),\left(c_{t}-y_{t}\right)$, and $\left(i_{t}-y_{t}\right)$, with the last two being observed. There will be one unobserved EC term missing from any observed-variables VECM. ${ }^{11}$ In Del Negro et al. (2007) it would be $\left(y_{t}-a_{t}\right)$, as output cannot be normalized by itself. ${ }^{12}$

To assess the impact of the exclusion of a latent error-correction term we return to the Poskitt and Yao (2017) and Ravenna (2007) model, adding an extra shock and observed variable. These are a preference shock to the period utility function, $b_{t}$, and an assumption that investment growth is observed. These choices mean that there is now an observed EC term, $\left(i_{t}-y_{t}\right)$, as well as a latent one, $\left(y_{t}-a_{t}\right)$. We assume that the preference shock follows

\footnotetext{
${ }^{10}$ The finding that a sticky-price model with a permanent technology shock can be well approximated by a short VAR is in contrast to the conclusion of Erceg, Guerrieri and Gust (2005). The difference is due to the fact that in the An and Schorfheide model the interest rate is an observed variable, whereas it is not in the rigid price model of Erceg et al. (2005).

${ }^{11}$ The presence of an unobserved EC term was also discussed in Liu, Pagan and Robinson (2018) in the context of the Rees, Hall and Smith (2016) model.

${ }^{12}$ It is not possible to eliminate this term using the resource constraint.
} 
a first-order autoregressive process and parameterize to match the same data moments as used by Ravenna (2007), producing $\rho_{b}=0.9$ and the standard deviation of its innovation as 0.006 .

In some instances, such as the responses of all variables to a labor supply shock, the omission of the latent error-correction term is of little consequence. Alternatively, Figure 4 compares the approximation of the observed and latent-variable VECMs to the impulse response of hours to a technology shock (left-hand side) and a preference shock (right-hand side). The latent-variable VECM provides a superior match, particularly for the response to a preference shock. This result reinforces our contention that latent-variable VECMs are a class of models which are likely to be useful to applied researchers when working with systems that contain a mixture of $\mathrm{I}(1)$ and stationary variables.

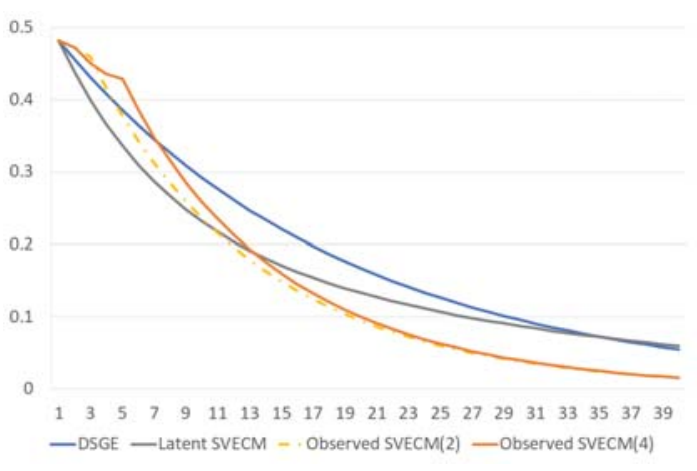

(a) Hours to a Technology Shock

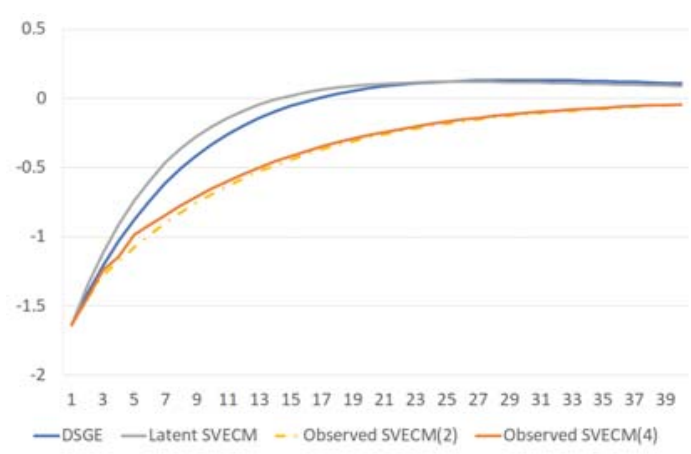

(b) Hours to a Preference Shock

Figure 4: Impulse Responses of Hours to a Technology or Preference Shock Using: (i) the RM of Poskitt and Yao (2017) (DSGE); (ii) a $\operatorname{VECM}(2)$ in the Observed Variables; (iii) a VECM(4) in the Observed Variables and (iv) a Latent-variable VECM

\subsection{Implications for Applied SVAR Research}

Sections 2.1 to 2.3 analyzed the magnitude of one of the main consequences of partial observability, namely truncation error, and discussed features of DSGE models in which it may occur. The extent of truncation error with even a $\operatorname{VAR}(2)$ was reasonably small, particularly for monetary-policy shocks. Typically in applied research the lag length is selected using an information criteria. However, different information criteria often suggest different lag 
lengths. Our results should give confidence to an applied researcher to use a relatively low lag length.

The second aspect emphasized was that truncation error often reflects the omission of stock variables from a VAR. In some cases this could be handled by careful choice of the other variables in the VAR. The level of net foreign assets or debt in a small-open economy VAR was a case where the omission of stock variables was of particular importance.

Finally, we argued that latent-variable VECMs are a useful approach to modeling macroeconomic systems containing a mixture of $\mathrm{I}(1)$ and $\mathrm{I}(0)$ variables.

\section{Partial Information and Identification: Estimating Contemporaneous Impulse Responses}

There are two dimensions to making a match of the RM and SVAR impulse responses. Impulse responses from any linear model will be a function of both the contemporaneous responses $C_{0}$ and the dynamics of the model through its implied VAR coefficients. ${ }^{13}$ In Section 2 we looked at the latter, as is true of most of the literature. Here we investigate what can be learnt about $C_{0}$ from information used in the RM. Put another way, it is a SVAR that has to be estimated now rather than a VAR. In the previous section we set $C_{0}^{S V A R}=C_{0}^{R M}$, but now our concern is with the estimation of $C_{0}^{S V A R}$, which requires structural identification information.

Some of the assumptions in the structural equations of RMs - e.g. exclusion restrictions - come from an economic model. Alternatively, others are purely statistical, e.g. that structural shocks are uncorrelated and the shocks are univariate ARs. Researchers estimating a SVAR in the observed variables often seek to have a great deal of flexibility in the dynamics, which can create issues when trying to estimate the contemporaneous responses consistent

\footnotetext{
${ }^{13}$ The $k^{\prime}$ th period ahead impulse responses of $z_{t}$ to $\varepsilon_{t}$ from a $\operatorname{SVAR}(\mathrm{p})$ in $z_{t}$, denoted by $C_{k}$, can be found recursively using $C_{k}=B_{1} C_{k-1}+\ldots+B_{p} C_{k-p}$, where $B_{j}$ are the VAR coefficients.
} 
with the RM, as they are not exploiting some of the statistical assumptions of those models. As we will see such restrictions could be used in the identification of the SVAR, although this has rarely been done in practice.

A typical structural equation in a RM, say for the variable $y_{t}$, has the form

$$
y_{t}=\alpha_{1} E_{t}\left(z_{t+1}\right)+\alpha_{2} x_{t}+\alpha_{3} y_{t-1}+u_{y t}
$$

where $x_{t}$ are other variables and $u_{y t}$ the shock. The issue is how to handle $E_{t}\left(z_{t+1}\right)$. The solution of the RM, Equation (1), implies $E_{t}\left(z_{t+1}\right)=B_{1} z_{t}+B_{2} z_{t-1}$. Letting $y_{t}=S z_{t}$, where $S$ is a selection matrix, Equation (9) can be expressed as

$$
y_{t}=\alpha_{1} S B_{1} z_{t}+\alpha_{1} S B_{2} z_{t-1}+\alpha_{2} x_{t}+\alpha_{3} y_{t-1}+u_{y t}
$$

and this constitutes a SVAR equation. The question then becomes whether we have enough instruments to estimate the parameters of this equation. That there may be enough comes from the assumption often used in RMs that $u_{y t}$ is a univariate $\operatorname{AR}(1)$, since this introduces non-linear restrictions between the parameters of the equation to be estimated.

To illustrate this we take as the RM a simple small New-Keynesian (NK) model of the form

$$
\begin{aligned}
& y_{t}=E_{t}\left(y_{t+1}\right)-\left(r_{t}-E_{t}\left(\pi_{t+1}\right)\right)+u_{y t} \\
& \pi_{t}=\beta E_{t}\left(\pi_{t+1}\right)+\kappa y_{t}+u_{\pi t} \\
& r_{t}=\rho_{r} r_{t-1}+\left(1-\rho_{r}\right)\left(\gamma_{y} y_{t}+\gamma_{\pi} \pi_{t}\right)+\delta \Delta y_{t}+\varepsilon_{r t},
\end{aligned}
$$

where $u_{y t}$ and $u_{\pi t}$ follow $\operatorname{AR}(1)$ processes with parameters $\rho_{y}$ and $\rho_{\pi}$ and innovations $\varepsilon_{y t}$ and $\varepsilon_{\pi t}$. All the innovations are assumed to be white noise processes and uncorrelated with each other. This is the external sector of the Reserve Bank of Australia's Multi-Sector Model (MSM), set out in Rees et al. (2016). We assume that $\pi_{t}$ and $r_{t}$ are observed. $y_{t}$ in the MSM 
actually is a stationized variable, However, we will initially abstract from that complication and think of $y_{t}$ as being an $I(0)$ observable output gap, in order to focus on the problems of matching the estimated $C_{0}^{S V A R}$ with $C_{0}^{R M}$. Later we return to the case where $y_{t}^{S}=y_{t}-a_{t}$, and $a_{t}$ is the log of technology, which follows an I(1) process with innovation $\varepsilon_{t}^{a}$.

Consider the New-Keynesian Phillips Curve in Equation (12). Now because the MSM solution is a $\operatorname{VAR}(1)$ in all variables expected inflation will be

$$
E_{t}\left(\pi_{t+1}\right)=b_{21}^{1} y_{t}+b_{22}^{1} \pi_{t}+b_{23}^{1} r_{t}
$$

where $b_{i j}^{1}(i=1, ., 3 ; j=1, . ., 3)$ denotes the elements in $B_{1}$. Using the estimated parameter values in Rees et al. (2016) this would be

$$
E_{t} \pi_{t+1}=.108 y_{t}+.269 \pi_{t}+.123 r_{t} .
$$

Once we replace $E_{t}\left(\pi_{t+1}\right)$ in Equation (12) with Equation (14) and re-arrange, the equation will have the form

$$
\pi_{t}=a_{21}^{0} y_{t}+a_{23}^{0} r_{t}+v_{\pi t},
$$

where $a_{21}^{0}=\frac{\beta b_{21}^{1}+\kappa}{1-\beta b_{22}^{1}}, a_{23}^{0}=\frac{\beta b_{23}^{1}}{1-\beta b_{22}^{1}}, v_{\pi t}=\rho_{\pi} v_{\kappa t-1}+\varepsilon_{\pi t}^{\prime}$ and $\varepsilon_{\pi t}^{\prime}=\frac{\varepsilon_{\pi t}}{1-\beta b_{22}^{1}}$. Equation (16) then becomes

$$
\left(1-\rho_{\pi} L\right) \pi_{t}=\left(1-\rho_{\pi} L\right) a_{21}^{0} y_{t}+\left(1-\rho_{\pi} L\right) a_{23}^{0} r_{t}+\varepsilon_{\pi t}^{\prime}
$$

It is evident that the coefficients on $\pi_{t-1}, y_{t-1}$ and $r_{t-1}$ all involve the same parameter $\rho_{\pi}$. Consequently, there is a common factor $\left(1-\rho_{\pi} L\right)$ in the three separate lag polynomials arising from a statistical assumption about the autoregressive nature of shocks. This common factor (COMFAC) structure was investigated by Hendry and Mizon (1978). 


\subsection{Using COMFAC Restrictions from the RM in SVAR Analysis}

A standard equation for inflation in a $\operatorname{SVAR}(1)$ containing $y_{t}, \pi_{t}$ and $r_{t}$ would be

$$
\pi_{t}=a_{21}^{0} y_{t}+a_{23}^{0} r_{t}+a_{22}^{1} \pi_{t-1}+a_{21}^{1} y_{t-1}+a_{23}^{1} r_{t-1}+\varepsilon_{\pi t} .
$$

There are five parameters to be estimated in the conditional mean of this but only three instruments, namely $y_{t-1}, r_{t-1}$ and $\pi_{t-1}$. When COMFAC restrictions are applied, Equation (18) becomes Equation (19) (which is equivalent to Equation 17), and there are only three parameters in that conditional mean, i.e. it is exactly identified.

$$
\pi_{t}=a_{21}^{0} y_{t}+a_{23}^{0} r_{t}+\rho_{\pi} u_{\pi t-1}+\varepsilon_{\pi t},
$$

To demonstrate how important the COMFAC restrictions may be to estimation, note that the parameters from Rees et al. (2016) imply the SVAR would have coefficient values of $a_{21}^{0}=0.197, a_{23}^{0}=.169$ and $\rho_{\pi}=.31$. Estimating Equation (19) using simulated data from the MSM (10,000 observations) and the instruments $\pi_{t-1}, y_{t-1}$, and $r_{t-1}$, we obtain the

estimates $\widehat{a_{21}^{0}}=0.197, \widehat{a_{23}^{0}}=.165$ and $\widehat{\rho_{\pi}}=0.31$, which are an excellent match to the true values, enabling the recovery of the MSM shock $\varepsilon_{\pi t}$.

In contrast, if one was to instead identify the SVAR by assuming that it is recursive, this would require assuming that the interest rate does not appear in the inflation equation (i.e. $a_{23}^{0}=0$ ). While it is true that $r_{t}$ is absent from the MSM's Phillips curve, it should appear in the SVAR equation for inflation because of expectations (the implied $a_{23}^{0}=.169$ ). So, for the inflation equation, the COMFAC restriction appears preferable to assuming it is recursive. It should be noted, however, that the COMFAC restriction does not necessarily produce strong instruments. 


\subsection{Identification Issues with Permanent and Transitory Shocks}

When there are $I(1)$ variables in the RM there must be permanent, as well as transitory, shocks. This mixture of shocks poses more substantial difficulties in making a match of $C_{0}^{S V A R}$ to that from the RM. In particular, the permanent shock identified in a SVAR may differ from that in the RM. To demonstrate this, we adopt the method for dealing with a mixture of shocks due to Shapiro and Watson (1988). ${ }^{14}$ They showed that one could separate permanent and transitory shocks by working with some modified equations in the SVAR. As an example, consider the MSM's structural output equation which has the form (after solving for the expectations)

$$
\begin{aligned}
y_{t}^{S} & =\alpha \pi_{t}+\delta r_{t}+v_{y, t} \\
v_{y, t} & =\rho_{y} v_{y, t}+\varepsilon_{y, t}^{\prime},
\end{aligned}
$$

where $\alpha=.77, \delta=-29.3$, and $\rho_{y}=.95$. Once again there is a common factor restriction. Now, if $\Delta y_{t}^{D}$ is the data then $\Delta y_{t}^{D}=\Delta y_{t}^{S}+\varepsilon_{t}^{a}$, and we have

$$
\Delta y_{t}^{D}=\alpha \Delta \pi_{t}+\delta \Delta r_{t}-\left(1-\rho_{y}\right) v_{y t-1}+\varepsilon_{y, t}^{\prime}+\varepsilon_{t}^{a} .
$$

This is the form of the equation that Shapiro and Watson would have estimated using $\pi_{t-1}$ and $r_{t-1}$ as instruments for $\Delta \pi_{t}$ and $\Delta r_{t}$. Notice, however, there are two shocks in Equation (20). Consequently, while the estimated equation does have a permanent shock, it will not be equal to the permanent shock of the RM, $\varepsilon_{t}^{a}$, unless $\varepsilon_{y t}=0$. This is an example of a more general problem that arises when there are more shocks than observed variables in the RM.

\footnotetext{
${ }^{14}$ Pagan and Pesaran (2008) extended this to handle co-integrated variables.
} 


\subsection{Implications for Applied SVAR Research}

The analysis and illustration shows the difficulties that a SVAR can experience in capturing the $C_{0}$ from a DSGE model often stem from the fact that the traditional estimation of SVAR models seeks to avoid imposing statistical restrictions (such as COMFAC), exclusion restrictions (in the interest rate equation $\pi_{t-1}$ does not appear in the MSM), and other constraints where coefficients are prescribed (for example that on $E_{t}\left(y_{t+1}\right)$ in the MSM output equation).

In many ways SVARs are about assembling information concerning the dynamics and contemporaneous interactions between variables in the macroeconomy in a way which, while identified, imposes less structure than is included in RMs. Traditionally this flexibility has been achieved by using exactly-identified SVARs, rather than the over-identified structural equations of the DSGE approach. There are, of course, common restrictions between the two approaches, such as the assumption that the structural shocks are uncorrelated. The COMFAC restrictions, being statistical in nature, could be implemented in a SVAR. ${ }^{15}$

\section{Researcher Initiated Partial Observability}

Partial observability can also occur by design. This happens in the literature when a researcher makes the assumption that the data and model variables are not the same. In Section 3 such a difference arose from the model structure, but now we consider when it involves including auxiliary equations which are assumed to connect the model variables and data. This is often referred to as "adding measurement error", although that term seems to imply that the "theory is ahead of data", and that the model is correct and the data is wrong. A more neutral description of the shock is that it provides a reconciliation between

\footnotetext{
${ }^{15}$ Suppose one imposes COMFAC restrictions on the SVAR model $A_{0} y_{t}=A_{1} y_{t-1}+u_{t}, u_{t}=\Phi u_{t-1}+\varepsilon_{t}$, where $\Phi$ is diagonal and $\operatorname{var}\left(\varepsilon_{t}\right)=I$. When there are no other restrictions on $A_{j}$ there are $2 n^{2}+n$ parameters to estimate. Since the model implies a $\operatorname{VAR}(2)$ there are $2 n^{2}+\frac{n(n+1)}{2}$ parameters in it. Hence the COMFAC restrictions result in an over-identified SVAR as $n<\frac{n(n+1)}{2}$. The system would be exactly identified if $\Phi$ was triangular.
} 
the model variables and the data, just as "wedges" are often devised to close the gap between the first order conditions of the RM and the data. The key issue is the appropriate specification of these reconciliation shocks, which we show will depend on the nature of the model variables, in particular whether they are $\mathrm{I}(1)$ or $\mathrm{I}(0)$.

\subsection{Model Variables are $I(0)$}

Denote the model variables as $z_{t}^{M}$ and the data $z_{t}^{D}$. Then one reconciles the two with $z_{t}^{D}=$ $z_{t}^{M}+\eta_{t}$, where $\eta_{t}$ is an error. Assuming the the RM has a SVAR of the form $A_{0} z_{t}^{M}=$ $A_{1} z_{t-1}^{M}+\varepsilon_{t}$, then an issue that immediately arises relates to whether the number of shocks now exceeds the number of observed variables. If they do then the shocks cannot all be recovered. At most we can recover the same number of $\operatorname{shocks}$ as $\operatorname{dim}\left(z_{t}^{D}\right)$ (or that many linear combinations of them). This is because the matrix connecting the vector of observed variables and the vector of shocks is not square and there is no unique inverse.

A class of models where such difficulties often arise are the components models that have been advanced to compute unobserved variables, such as the output gap. One can certainly make estimates of the shocks but these do not converge to what the model would define them to be as the sample size expands. To see this in a very simple context suppose that $z_{t}=\varepsilon_{t}+\eta_{t}$, the variance of $\eta_{t}$ is known, and $\varepsilon_{t}$ and $\eta_{t}$ are uncorrelated and n.i.d. $(0,1)$. Then the minimum mean square error estimate of either $\varepsilon_{t}$ or $\eta_{t}$ will be some multiple of $z_{t}$, namely $\hat{\varepsilon}_{t}=.5 z_{t}=.5\left(\varepsilon_{t}+\eta_{t}\right)$, but will never actually equal $\varepsilon_{t}$. This outcome does not change if there is serial correlation in the shocks. Notice that the one unit contemporaneous impulse response of $z_{t}$ to $\varepsilon_{t}$ is correctly estimated to be unity because $z_{t}=\hat{\varepsilon}_{t}+\hat{\eta}_{t}$. Indeed, this is generally true, as the ability to estimate impulse responses, rather than shocks, simply resides in whether one can estimate the model parameters, and so is an issue of identification.

There are many examples of this type of model. Fleischman and Roberts (2011) present a state-space model to extract an output gap that involves 8 observed variables and 9 shocks, meaning that the shocks cannot be exactly extracted and raising questions over whether the 
output gap might involve supply-side shocks.

\subsection{Model Variables are $I(1)$}

A common approach to introducing measurement error in the case where variables are I(1) is to write $\Delta z_{t}^{D}=\Delta z_{t}^{M}+\eta_{t}$, where $\eta_{t}$ is $I(0)$. A recent application in this vein is Aruoba et al. (2016). They considered that different measures of GDP growth could be regarded as deviating from true GDP growth, and that these deviations would be described as measurement errors. Many factor models make a similar assumption. In terms of models with a greater economic emphasis, DSGE models often proceed in this way, e.g. Guerron-Quintana (2010), including those used at policy institutions, e.g. Chung et al. (2010) and Rees et al. (2016). This wide usage motivates our analysis of the implications of this partial observability specification.

We start with a simple situation which parallels that in Aruoba et al. (2016). Let $\Delta z_{t}$ be the true growth rate in GDP and $\Delta z_{j t}(j=1,2)$ be two noisy measures of it. Then we have $\Delta z_{j t}=\Delta z_{t}+\eta_{j t}$, where $\eta_{j t}$ are said to be the measurement errors, which Aruoba et al. (2016) assume to be white noise. Now consider what this means for the relation between the level of GDP and its measures. Selecting the first data series we have

$$
\begin{aligned}
z_{1 t}-z_{t} & =\sum_{k=1}^{t}\left(\Delta z_{1 k}-\Delta z_{k}\right) \\
& =\sum_{k=1}^{t} \eta_{1 k} .
\end{aligned}
$$

Consequently, under the assumption that measurement errors are white noise it is clear that the data, $z_{1 t}$, and model variable, $z_{t}$, do not co-integrate. Moreover, the difference

$$
\begin{aligned}
z_{1 t}-z_{2 t} & =\sum_{k=1}^{t}\left(\Delta z_{1 k}-\Delta z_{2 k}\right) \\
& =\sum_{k=1}^{t}\left(\eta_{1 k}-\eta_{2 k}\right),
\end{aligned}
$$


would also be $I(1)$. Therefore, unless $\eta_{1 k}$ and $\eta_{2 k}$ are perfectly correlated, there would be no co-integration between either of the data variables $z_{1 t}$ and $z_{2 t}{ }^{16,17}$

Now it may be that the observed and model variables are not co-integrated, but it would seem more satisfactory if at least one of the measured quantities did co-integrate with the true level of GDP. Therefore it doesn't seem sensible to rule this out when choosing the specification of the measurement error. One can, of course, test if the data $z_{1 t}$ and $z_{2 t}$ are co-integrated, which provides a check on whether the assumptions being made about the measurement error are reasonable. Aruoba et al. (2016) take $z_{1 t}$ to be the expenditure-based measure of GDP, while $z_{2 t}$ is the income-based series. We therefore test if they co-integrate; using a $\operatorname{VAR}(2)$, Johansen's trace and eigenvalue tests are equal and of value 3.22. As the $5 \%$ critical value is 3.84 there does seem to be co-integration between the observed series, and a useful re-specification of their model would be to include error-correction terms. ${ }^{18}$ It is interesting that the cointegrating vector seems to be $\left(\begin{array}{ll}1 & -.9978\end{array}\right)$.

How can measurement error be introduced into a model in a way that maintains the cointegrating relationships? One could instead write $z_{j t}^{D}-z_{j t}^{M}=\eta_{j t}$ for all $j$ elements of $z_{t}^{D}$, and assume that $\eta_{j t}$ are $I(0)$. Then $\Delta z_{j t}^{D}=\Delta z_{j t}^{M}+\Delta \eta_{j t}$, which clearly results in cointegration between model and data variables being maintained. The only remaining issues is to determine an appropriate specification for $\eta_{t}$. One possibility is to assume it is i.i.d. To see another possible definition, note that if we assume that the data and model variables co-integrate with the same cointegrating vectors, we would have equations for the model of the form

$$
\Delta z_{t}^{M}=\delta \gamma^{\prime} z_{t-1}^{M}+C e_{t}^{M}
$$

where $\delta$ and $C$ are parameters, $e_{t}^{M}$ the model shocks, and $\gamma$ are the common cointe-

\footnotetext{
${ }^{16}$ If they were perfectly correlated then basically $z_{1 t}$ and $z_{2 t}$ would be the same series.

${ }^{17}$ This is also true if the $\mathrm{I}(1)$ data is filtered to produce $\mathrm{I}(0)$ processes that are used in models e.g. as an output gap. In those cases the filtered data will be weighted averages of growth rates in variables so it is an average of growth rates in the data that would be held to deviate from model growth. Thus, the issues we describe in this section also apply when filtered data are used, although the analysis is more complex.

${ }^{18}$ We thank Dongho Song for providing the data.
} 
grating vectors. ${ }^{19}$ Then, using the relationship between the observed data and the model counterparts, $\Delta z_{t}^{D}=\Delta z_{t}^{M}+\Delta \eta_{t}$, we obtain

$$
\left(\Delta z_{t}^{D}-\Delta \eta_{t}\right)=\delta \gamma^{\prime}\left(z_{t-1}^{D}-\eta_{t-1}\right)+C e_{t}^{M}
$$

and therefore

$$
\Delta z_{t}^{D}=\delta \gamma^{\prime} z_{t-1}^{D}+\eta_{t}-\left(1+\delta \gamma^{\prime}\right) \eta_{t-1}+C e_{t}^{M}
$$

Now we would want the shocks in this VECM, $e_{t}^{\eta}$, to be i.i.d., and so

$$
\eta_{t}=\left(1+\delta \gamma^{\prime}\right) \eta_{t-1}+e_{t}^{\eta}-C e_{t}^{M}
$$

Hence in this second definition the measurement-error shocks $\eta_{t}$ follows a VAR process with innovations constructed from $e_{t}^{\eta}$ and the model shocks $e_{t}^{M} \cdot{ }^{20}$ Often one sees measurementerror shocks specified as univariate $\mathrm{AR}(1)$ processes but this leads to complicated VECM processes. A better specification is to utilize the form in Equation (22), which exploits model cointegrating information and the model shocks as well as the measurement error innovation $e_{t}^{\eta} \cdot{ }^{21}$

\subsubsection{Implications for Applied Research}

To implement either definition of $\eta_{t}$, in the state-space model the measurement equations would be $\Delta z_{t}^{D}=\Delta z_{t}^{M}+\Delta \eta_{t}$, as is normally done, but now $\eta_{t}$ is a state variable, rather than $\Delta \eta_{t}$ being assumed to be n.i.d. The state equations include those for the model variables, namely Equation (21), and those governing the evolution of $\eta_{t}$, e.g. Equation (22).

\footnotetext{
${ }^{19}$ The model shocks will be assumed to be white noise processes, i.e. they are innovations, although they only need to be $I(0)$ processes for our analysis.

${ }^{20}$ Introducing lags of $\Delta z_{t}^{M}$ into Equation (21) increases the order of the VAR in $\eta_{t}$.

${ }^{21}$ This can be generalized to the case where the cointegrating vectors among the observables are not the same as the model. In this case $\eta_{t}$ has to compensate for that difference as well.
} 


\section{Conclusion}

What influences the ability of a SVAR to make a match with the impulse responses of representative models such as DSGEs? Since DSGE models typically include variables that are not observed in estimation, we have looked at when these unobserved variables can be expressed as a function of the observed variables. If the weights on the higher-order lags of the observed variables are low it may be possible to approximate the responses well with a finite-order VAR. Stock variables, which are typically included as latent variables in DSGE models but are not included in SVAR models, emerged as a potentially important factor influencing the extent of truncation bias. A small-open economy model showed that the omission of the stock of foreign debt from a VAR could result in truncation biases for real shocks, although this was an issue mainly at longer horizons.

Analysis of the well-known Smets and Wouters (2007) model found that the major source of the truncation problem with it was the assumption that the interest rate rule depended on the flex-price output gap and related terms. While theoretically appealing, applied work frequently involves a monetary rule with an observed output term or output growth. Changing the rule to this greatly reduced the truncation bias.

DSGE models today often include permanent shocks, such as technology. It was found that in this case an important source of truncation bias was a misspecification of the VECM, as the actual generating process is a latent-variable one and not just in observed variables. Using the Poskitt and Yao (2017) model it was demonstrated that the quality of the match to the DSGE impulse responses can be considerably improved by estimating a latent-variable VECM.

Our findings suggest that an important factor contributing to the divergent findings which exist in the literature about the ability of SVARs to make a match with the impulse responses from DSGE models is whether or not the DSGEs being analyzed include permanent shocks.

In all, it appears that while the extent of truncation bias is model dependent, it is often not substantial, and can be lessened by strategies such as a careful choice of the observed 
variables and working with a latent-variable VECM.

The second dimension to making a match is how well the SVAR can capture the initial impulse responses rather than the dynamics. It was shown that some of the identification coming from DSGE models arises from assumptions made about the shock processes. These are statistical, rather than economic, restrictions. They imply that there are common factors in the SVAR. Using these restrictions in the identification of the SVAR can considerably improve the match.

Finally, we examined another case of partial observability of variables. This involved the common practice of treating model variables as deviating from observed data due to measurement error. It was shown that this strategy has to treated carefully. It can result in more shocks than observed variables and hence an inability to extract the model shocks. Other difficulties arise when data is I(1), where the inclusion of measurement error may imply a lack of co-integration between the data variables. It was demonstrated how to specify measurement-error processes that would preserve any cointegrating information. 


\section{References}

An, S. and F. Schorfheide (2007), "Bayesian Analysis of DSGE Models", Econometric Reviews, 26, $113-172$.

Aruoba, B., F.X. Diebold, J. Nalewaik, F. Schorfheide and D. Song (2016), "Improving GDP Measurement: A Measurement Error Perspective" Journal of Econometrics, 191, 384-397

Binder, M. and M. H. Pesaran (1995), "Multivariate Rational Expectations Models and Macroeconomic Modelling: A Review and Some New Results", in M.H. Pesaran and M. Wickens (eds.) Handbook of Applied Econometrics: Macroeconomics, Basil Blackwell, Oxford.

Blanchard, O. J. and C. M. Kahn (1980), "The Solution of Linear Difference Models under Rational Expectations", Econometrica, 48, 5, 1305-1311.

Brayton, F. T. Laubach and D. Reifschneider (2014), "The FRB/US Model: A Tool for Macroeconomic Analysis", FEDS Notes.

Canova, F. and F Ferroni (2018) "Mind the Gap! Stylized Dynamic Facts and Structural Models", mimeo.

Chari, V. V., P.J. Kehoe and E.R. McGrattan (2005), "A Critique of Structural VARs Using Business Cycle Theory", Federal Reserve Bank of Minneapolis Working Paper, 631.

Christiano, L.J., M. Eichenbaum and Robert Vigfusson (2007), "Assessing Structural VARs", in D. Acemoglu, K. Rogoff and M. Woodford (eds.), NBER Macroeconomics Annual 2006, 21, $1-106$.

Chung, H, M.T. Kiley, and J-P Laforte, (2010) "Documentation of the Estimated, Dynamic, Optimization-based (EDO) Model of the U.S. Economy", Finance and Economics Discussion Series, 2010-29, Board of Governors of the Federal Reserve System.

Del Negro, M., F. Schorfhiede, F. Smets and R. Wouters (2007), "On the Fit of New Keynesian Models", Journal of Business and Economic Statistics, 25, 2, 123-143.

Erceg, C. J., L. Guerrieri and C. Gust (2005), "Can Long-Run Restrictions Identify Technology Shocks?", Journal of the European Economic Association, 3, 1237-1278.

Fernández-Villaverde, J., J. F. Rubio-Ramírez, T. J. Sargent and M. W. Watson (2007), "ABCs (and Ds) of Understanding VARs," American Economic Review, 97, 1021-1026. 
Fleischman, C.A. and J. M. Roberts (2011) "From Many Series, One Cycle: Improved Estimates of the Business Cycle from a Multivariate Unobserved Components Model", Finance and Economics Discussion Series, 2011-46, Federal Reserve Board.

Franchi, M. and A. Vidotto (2013), "A Check for Finite Order VAR Representations of DSGE Models", Economics Letters, 20, 1, 100-103.

Giacomini, R. (2013), "The Relationship Between VAR and DSGE Models", in T. B. Fomby, L. Kilian and A. Murphy (eds.), VAR Models in Macroeconomics - New Developments and Applications: Essays in Honor of Christopher A. Sims, Advances in Econometrics, 32, 1-25.

Guerron-Quintana, P. (2010), "What You Match Does Matter: The Effects of Data on DSGE Estimation", Journal of Applied Econometrics, 25, 774-804

Hendry, D. F. and G. Mizon (1978), "Serial Correlation as a Convenient Simplification, Not a Nuisance: A Comment on a Study of the Demand for Money by the Bank of England," Economic Journal, 88, 549-63.

Justiniano, A. and B. Preston (2010), "Can Structural Small Open-Economy Models Account for the Influence of Foreign Disturbances?", Journal of International Economics, 81, 61-74.

Kapetanios, G., A.R. Pagan and A. Scott (2007), "Making a Match: Combining Theory and Evidence in Policy-oriented Macroeconomic Modeling", Journal of Econometrics, 136, 505-594.

Liu, X., A. R. Pagan and T. Robinson (2018), "Critically Assessing Estimated DSGE Models: A Case Study of a Multi-sector Model", Economic Record, 94, 349-371.

Morris, S.D. (2016), "VARMA Representation of DSGE Models", Economics Letters, 138, 3033.

Ouliaris, S., A.R. Pagan and J. Restrepo (2018) Quantitative Macroeconomic Modeling with Structural Vector Autoregressions - An EViews Implementation, available at http://www.eviews.com/StructVAR/structvar.html

Pagan, A. R. (2017), "Some Consequences of Using 'Measurement Error Shocks' When Estimating Time Series Models", Centre for Applied Macroeconomic Analysis Working Paper, Australian National University, 2017-12.

Pagan, A.R. \& M. H. Pesaran (2008) "Econometric Analysis of Structural Systems with Permanent and Transitory Shocks," Journal of Economic Dynamics and Control, 32, 10, 3376-3395. 
Pagan, A.R. \& T. Robinson (2016), "Investigating the Relationship Between DSGE and SVAR Models," NCER Working Paper Series 112, National Centre for Econometric Research.

Poskitt, D. and Yao, W. (2017), "Vector Autoregressions and Macroeconomic Modelling: an Error Taxonomy", Journal of Business and Economics Statistics, 35, 3, 407-419.

Ravenna, F. (2007), "Vector Autoregressions and Reduced Form Representations of DSGE Models", Journal of Monetary Economics, 54, 7, 2048-2064.

Rees, D.M., P. Smith and J. Hall (2016), "A Multi-sector Model of the Australian Economy", Economic Record, 92, 298, 374-408.

Schmitt-Grohe, S. and M. Uribe (2003), "Closing Small Open Economy Models", Journal of International Economics, 61, 163-185.

Shapiro M. and M. Watson (1988), "Sources of Business Cycle Fluctuations", in NBER Macroeconomics Annual, 3, 111-148.

Smets, F. and R. Wouters (2007), "Shocks and Frictions in US Business Cycles: a Bayesian DSGE Approach", American Economic Review, 97, 586-606.

Uhlig, F. H. (1999), "A Toolkit for Analysing Nonlinear Dynamic Stochastic Models Easily", in R. Marimon and A. Scott (eds.), Computational Methods for the Study of Dynamic Economies, Oxford University Press, 30-61. 


\section{Appendix A State-space Representation of the VECM}

The model is given by Equations (7) and (8), coupled with the measurement equation given by Poskitt and Yao (2017) and their assumption that technology growth is uncorrelated. Denoting the observed variables with a superscript obs, the state-space form of the latent-variable VECM includes the measurement equations:

$$
\left[\begin{array}{c}
\Delta y_{t}^{o b s} \\
h_{t}^{o b s}
\end{array}\right]=\left[\begin{array}{ccc}
1 & 0 & -1 \\
0 & 1 & 0
\end{array}\right]\left[\begin{array}{c}
y_{t}^{s} \\
h_{t} \\
y_{1 t}^{s}
\end{array}\right]+\left[\begin{array}{c}
\epsilon_{t}^{a} \\
0
\end{array}\right]
$$

where $y_{1 t}^{s}$ is the lag of $y_{t}^{s}$.

The transition equations are:

$$
\left[\begin{array}{c}
y_{t}^{s} \\
h_{t} \\
y_{1 t}^{s}
\end{array}\right]=\left[\begin{array}{ccc}
\left(1+a_{11}\right) & a_{12} & 0 \\
a_{21} & a_{22} & 0 \\
1 & 0 & 0
\end{array}\right]\left[\begin{array}{c}
y_{t-1}^{s} \\
h_{t-1} \\
y_{1 t-1}^{s}
\end{array}\right]+\left[\begin{array}{cc}
c_{11} & \left(c_{12}-1\right) \\
c_{21} & c_{22} \\
0 & 0
\end{array}\right]\left[\begin{array}{c}
\epsilon_{t}^{h} \\
\epsilon_{t}^{a}
\end{array}\right]
$$

where $a_{i j}$ denotes the $j^{\prime}$ th coefficient in the $i^{\prime}$ th transition equation to be estimated $(i, j=1$ and 2), and the standard deviations of $\epsilon_{t}^{h}$ and $\epsilon_{t}^{a}$. $c_{i j}$ are the contemporaneous impulse responses, which are fixed to those from the RM, as in Section 2. 